\title{
Vulnerability Assessment of Buildings against Earthquake Case Study: Qadghoon Neighborhood, Borujerd, Iran
}

\author{
Hasan Hekmat $^{1}$, Ali Hosseini ${ }^{1} \mathbb{D}$ \\ Date of submission: 19 Sep. 2020, Date of acceptance: 26 Dec. 2020
}

\begin{abstract}
INTRODUCTION: The buildings, as the main and most abundant elements in cities, have great importance in two aspects of assessing and mitigating the vulnerability at disaster incidence. On the other hand, the emphasis of post disaster reconstruction engineers on the single-scale building has compounded the importance of building in terms of planning to reduce the damages of disaster incidence.

METHODS: This quantitative-descriptive study was conducted documentary studies and extraction of priority indicators determining the degree of vulnerability. This research aimed to assess the vulnerability of Qadghoon buildings, one of the historical neighborhoods of Borujerd, Lorestan Province, Iran, which was damaged and reconstructed after the 2007 earthquake, for more than a decade.
\end{abstract}

Original Article

FINDINGS: The data obtained from the field study of this neighborhood were analyzed after entering into GIS software and weighted by Analytic Hierarchy Process-Delphi. The provided maps were evaluated and the vulnerability score obtained from indicators was weighted by the above method. Finally, the score of vulnerabilities in neighborhoods in the range of 0-5 Likert scale was calculated at 3.5208 , which indicated a moderate increase in vulnerability.

CONCLUSION: After the examination of actions taken in the post-earthquake reconstruction process, reduction of vulnerability evaluation was low. This result indicated the failure of operators to reduce the vulnerability on a scale of buildings, despite the large opportunities and resources. In addition to lessons from the present study, some suggestions were provided to improve the process of reconstruction after possible disasters in the future.

Keywords: Borujerd; Earthquake; Qadghoon Neighborhood; Single-scale of Building; Vulnerability Assessment.

How to cite this article: Hekmat $\mathrm{H}$, Hosseini A. Vulnerability Assessment of Buildings against Earthquake Case Study: Qadghoon Neighborhood, Borujerd, Iran. Sci J Rescue Relief 2020; 12(4): 311-22.

\section{Introduction}

$\mathrm{T}$ The vulnerability of buildings, as the physical composing elements of cities and neighborhoods, would eventually lead to the vulnerability of the whole urban system. It seems that during recent years, this feature has had greater impacts on the post-disaster reconstruction plans, compared to other elements. Borujerd, Lorestan Province, Iran, as one of the high-risk cities in terms of natural disasters, especially earthquakes (with a very highfrequency occurrence), was struck by an earthquake measuring 6.1 on the Richter scale.
This incident destructed many urban buildings, especially those located in the central parts of the city. The historical sites of Dodangeh, Sufyan, Yakhchal, and Razan (including the Qadghoon neighborhood), Borujerd, Lorestan Province, Iran, were among the most important areas facing serious damages as a result of earthquake and reconstruction process implemented after that. For this reason, the Qadghoon neighborhood was selected as a part of this area, with many identity features due to the SadatShahr residence, to be investigated as the research study sample. One of the most important goals of the post-disaster

1-Lecturer, Department of Architecture Engineering, Faculty of Civil Engineering and Architecture, Shahid Chamran University of Ahvaz, Ahvaz, Iran

Correspondence to: Hasan Hekmat, Email: h.hekmat@scu.ac.ir 
reconstruction process is to reduce the vulnerability of the disaster area to future disasters.

After the earthquake hit the Qadghoon neighborhood in 2006, the post-earthquake reconstruction process began in this area, and it seems that after more than a decade, most of this process has been completed. However, despite the huge expenditure of financial and human resources, this process has not been able to reduce the vulnerability of the neighborhood and bring it to a standard level, in the face of future disasters.

The failure of spending time and cost on reconstruction to reduce vulnerability is one of the most important issues that is specific to this particular case and is evident in most similar situations in the past century, both post-disaster and post-war reconstruction. One of the most important reasons for this series of failures is the lack of attention to the past experiences of reconstruction in the country. This issue can be solved by documenting and evaluating past experiences. Therefore, this study aimed to document and assess the vulnerability of the Borujerd neighborhood, to learn lessons in similar future processes. Furthermore, examining and determining the extent of changes in the vulnerability of neighborhood buildings during the reconstruction process (comparative comparison with the situation before the accident), was the next priority of this research.

This study was carried out with the above objectives and using priority indicators to determine the vulnerability of buildings in the study area (Qadghoon neighborhood). Regarding the completion of reconstruction process after 2006 earthquake of Borujerd and the expectation of reduction in the vulnerability of city buildings (first priority of reconstruction process), the evaluation of reconstruction process result based on standard values, and awareness of current vulnerability of neighborhood are very important. Therefore, this study seeks to answer the following three questions:

- What is the physical vulnerability of buildings (public (The building had public usage which would provide services like accommodation, management, and health services during and after the disaster and were accessible by all, e.g., offices, schools, mosques, ... .) and private) in the Qadghoon neighborhood in terms of priority indicators, namely geometric disorder, poor execution, cultural heritage protection, construction technology, supervisory systems and rules existence, and geometric or structural heterogeneous buildings? In which of these areas is the vulnerability more critical and in which is it more favorable?

- Critically and comparatively, given the available evidence, has the post-disaster reconstruction process been able to reduce the vulnerability of city buildings in priority indicators, compared to the pre-disaster situation? From this perspective, has this process been able to achieve its main goal, which is to reduce the vulnerability of the neighborhood at the building scale?

- What would any suggestions be offered to be learned in similar future processes?

\section{Review of the literature}

This section summarizes some similar experiences in the field of vulnerability assessment of urban buildings. These experiments have been performed abroad and at home.

- In 1999, Cava used geographic information system (GIS) to map vulnerabilities and used such information as topography and fault location in his model(1);

- Antonioni and Cruzani used the data collection of urban buildings using image analysis, fieldwork, the use of Google to see cities, and the use of statistics inferred in the evaluation method (1);

- In his doctoral dissertation, Botero assesses the role of geographic information and data in evaluating urban vulnerability to earthquakes and designate zones the extent of social and physical vulnerability in Medellin, Colombia (2);

- Mittal first assesses the extent of building vulnerability using vulnerability models, including the Risk-U model. Finally, by presenting earthquake scenarios at different intensities, he estimates and models the damage caused by possible earthquakes (3);

- Wolfe and Heikkala consider three factors as important in the vulnerability of regions. These three factors include age and stage of development in the geographical area, morphology of development, political and religious decision-making(4);

- Banreji examined the vulnerability of a neighborhood. This was achieved by graphically drawing various features that require fieldwork and providing solutions for physical improvement. He also prepared a map for each of the 
indicators and identified the vulnerable areas of that indicator. The city vulnerability scale is a criterion for determining vulnerabilities and its simplest form is a linear and scoring function, which is the final score of the weighted average score of each of the indicators (5).

A summary of some of the experiences in similar domestic examples is also given below:

- Habibi has determined the structural factors affecting the vulnerability of the ancient fabric of Zanjan using GIS and fuzzy logic. Mohammadzadeh has reduced the seismic damage and its research method is implemented by developing a questionnaire scored on a Likert scale. He then examines the height and type of use using GIS (1)(6);

- In an article, Agha Taher has weighed the factors affecting the seismic vulnerability of Tehran. Moreover, Azizi and Akbari have expressed some urban planning considerations in measuring the vulnerability of cities to earthquakes, and used these considerations by applying the method of hierarchical analysis and GIS (7);

- The Deputy of Urban Planning and Architecture of Tehran Municipality, Tehran, Iran, has identified urban blocks with worn texture in the city of Tehran, and GIS software has been used in analyzing the input data and extracting its output maps. The defined criteria for determining blocks with worn texture are as follows: a block in which at least $50 \%$ of the property has an area of fewer than $100 \mathrm{~m}^{2}$;a block where at least $50 \%$ of the buildings are worn out; and a block with at least $50 \%$ of its passages (before correction) is less than 6 meters or less than the standard of urban planning (8);

- Ghanbari, with emphasis on the optimal location of special uses with GIS, has studied the city of Tabriz, Iran, in terms of the indicators of population density, building density, land price, building age, building materials, land use compatibility. He also investigated access based on the width of the streets, and through the analytic hierarchy process (AHP) method and binary matrix, applied evaluation criteria to weigh them, and finally, by assessing in the GIS, the vulnerability of each indicator was separately considered and related reviews and maps were produced in general (9);

- With a concurrent strategy, Shirozhan has studied the urban vulnerability of the 17th district of Tehran by using land-use, density, open space, and accessibility indicators, and analyzing these indicators through the strengths, weaknesses, opportunities, and threats (SWOT) method (10);

- Shieh et al. concentrated on using the inversion hierarchical weight process (IHWP) method, which is a combination of fuzzy logic and hierarchical analysis, to evaluate the steps of presenting selected indicators, provide inverse hierarchical analysis of indicators that are evaluated to determine the vulnerability of the selected areas, rate using AHP, and combine maps and vulnerability mapping (11);

- Ahadnejad and Jalilpour have investigated the amount of human losses and economic damages to the buildings of a city using the AHP hierarchical method, analytical and demonstrative facilities of the GIS system, presenting earthquake scenarios, modeling, and microzoning of damages to buildings (12);

- Monzavi et al. have identified the main areas and factors of vulnerability of old spaces and textures, the pattern of population distribution and its effect on the vulnerability of spaces and textures worn by earthquakes, the type and system of activity and its impact on the vulnerability of spaces and textures worn by earthquakes, and the effect of building age and materials on the vulnerability of urban spaces and textures, and they have made efforts to develop a conceptual framework (13);

- Hamidi has assessed the vulnerability of the elements that make up the city, namely the building, the composition of the texture, the roads, and the pattern of use. Additionally, to explain how to evaluate each of these elements, he divided them into three stages, namely assessing the proximity of elements of physical structure, evaluating the composition of elements of physical structure and sequence of earthquake stages, and evaluating the composition formed city elements (e.g., texture, construction, location) (14);

It can be seen that the weighting technique using the opinion of experts and then modeling using GIS software has the highest frequency among studies and surveys. One of the most important advantages of this method is the possibility of using a large number of indicators, which will increase the accuracy of the study. The 
use of the integrated SWOT analysis method has gained the second rank in the frequency table. This method is especially beneficial since it provides a comprehensive view of the phenomenon under study, along with opening new windows to the study domain in the form of internal and external facilities and constraints.

\section{Methods}

The method of this research was determined after reviewing the experiences and methods of vulnerability assessment, summarizing the background, and considering the frequency of approaches, tools, and methods. Therefore, this research has been performed with a quantitative approach and a descriptive method.

According to Table 2, it is clear that GIS modeling software is the most frequent software in the field of vulnerability assessment, and the field study method is the most popular ones. Furthermore, slightly different, distant measurement and relying on spatial data infrastructures are the second most popular methods of data collection. According to the above studies, in this study, the data obtained from the field study were entered into GIS software, and the weight of each index relative to the others was determined using AHP-Delphi hierarchical analysis method. After the preparation of the map according to the indicators, the vulnerability number of the neighborhood in each indicator was determined. Finally, the number of vulnerabilities in the neighborhood was estimated from the perspective of existing buildings.

In the following section, the priority indicators that determine the vulnerability of buildings are presented, which are extracted after studying the documents (literature review) and interviewing experts. It is expected that after studying the values of these indicators, the vulnerability of the neighborhood in the field of construction be determined with an appropriate approximation. Priority indicators determining the vulnerability of neighborhood buildings are presented in Table 3 with reference to the source.

\section{Understanding the field of research}

Borujerd city is on the west of the country, with geographical characteristics of $33^{\circ} 53^{\prime} \mathrm{N} 48^{\circ} 4^{\prime} \mathrm{E}$. The distance from this city to Tehran is $390 \mathrm{~km}$. Moreover, it is 1,540 meters above sea level and $1,606 \mathrm{~km}^{2}$ wide (16). Figure 1 depicts the

Table 1. Indicators for measuring physical vulnerability in research

\section{Index (authors)}

1. The asymmetrical buildings (private and public) and their frequencies in the blocks;(14-17)

2.Poor and wrong construction of new buildings; $(12,18,19)$

3. The amount of preservation and restoration of old areas and cultural heritage;(20)

4. Different structures and construction technologies; $(21,22)$

5. Age of buildings;(15)

6. Constructed buildings under construction supervisions and codes;(15)

7. The observation of construction rules and the number of state supervisors on the construction process in a neighborhood; $(8,21)$

8. Heterogeneous buildings (the number and location of old and damaged, or high and damaged buildings, large size structures, and special structures); $(23,24)$

Table 2. Weighing and calculating the vulnerability number of neighborhood buildings using analytic hierarchy process

\begin{tabular}{|c|c|c|c|c|c|c|c|c|c|c|c|}
\hline Sub-index & Irregularity & $\begin{array}{c}\text { Poor } \\
\text { construction }\end{array}$ & $\begin{array}{l}\text { Lack of } \\
\text { restoration }\end{array}$ & $\begin{array}{c}\text { Poor } \\
\text { structure }\end{array}$ & longevity & $\begin{array}{l}\text { Lack of } \\
\text { supervision } \\
\text { laws }\end{array}$ & Incompatibility & $\begin{array}{c}\text { Geometric } \\
\text { mean }\end{array}$ & Eigenvector & $\begin{array}{c}\text { Vulnerability } \\
\text { number }\end{array}$ & $\begin{array}{c}\text { Weight } \\
\text { vulnerability }\end{array}$ \\
\hline Irregularity & 1 & 1 & 2 & 1 & 2 & 1 & 1 & 1.219 & 0.1505 & 4 & 0.602 \\
\hline $\begin{array}{c}\text { Poor } \\
\text { construction }\end{array}$ & 1 & 1 & 2 & 1 & 2 & 1 & 1 & 1.219 & 0.1505 & 4 & 0.602 \\
\hline $\begin{array}{l}\text { Lack of } \\
\text { restoration }\end{array}$ & 0.5 & 0.5 & 1 & 0.5 & 1 & 0.5 & 0.5 & 1 & 0.1235 & 5 & 0.6175 \\
\hline $\begin{array}{l}\text { Poor structure } \\
\text { longevity }\end{array}$ & $\begin{array}{c}1 \\
0.5\end{array}$ & $\begin{array}{c}1 \\
0.5\end{array}$ & $\begin{array}{l}2 \\
1\end{array}$ & $\begin{array}{c}1 \\
0.5\end{array}$ & $\begin{array}{l}2 \\
1\end{array}$ & $\begin{array}{c}1 \\
0.5\end{array}$ & $\begin{array}{c}1 \\
0.5\end{array}$ & $\begin{array}{c}1.219 \\
1\end{array}$ & $\begin{array}{l}0.1505 \\
0.1235\end{array}$ & $\begin{array}{c}3.6 \\
3.28\end{array}$ & $\begin{array}{c}0.5418 \\
0.405\end{array}$ \\
\hline $\begin{array}{l}\text { Lack of } \\
\text { supervision } \\
\text { laws }\end{array}$ & 1 & 1 & 2 & 1 & 2 & 1 & 1 & 1.219 & 0.1505 & 1 & 0.1505 \\
\hline $\begin{array}{c}\text { Incompatibility } \\
\text { Sum }\end{array}$ & 1 & 1 & 2 & 1 & 2 & 1 & 1 & $\begin{array}{l}1.219 \\
8.095\end{array}$ & 0.1505 & 4 & $\begin{array}{c}0.602 \\
3.5208\end{array}$ \\
\hline
\end{tabular}

Table 3. Lessons learned and some suggestions that can be made from the study process and research results (authors) 
Attention to urban planning and design in parts that cannot withstand the passage correction and as a result either become barren land or leave a building with $100 \%$ density with long consoles. (Problematic geometry of parts)

Paying attention to the number of blocks with irregular and unusual parts, large size and high number of parts, in the neighborhood and reducing these vulnerable factors in the blocks through logical ways of improvement such as various methods of assembling parts (problematic parts in blocks)

Stronger oversight of the implementation of approved and amended policies, as well as planning to increase the skills of contractors and building contractors to reduce the number of poor performances and human errors in implementation (stronger supervision, increasing executive skills)

The need for expert supervision and experienced executive staff on these measures, because in the 2006 earthquake, buildings with low strength materials were damaged due to structural weakness and durable buildings due to improper execution. (Employing experienced supervisors)

Utilizing the potential of improving and reducing the vulnerability of buildings with textured building materials, by improving this building instead of renovation to reduce vulnerability (improvement instead of renovation)

Improvement of less valuable buildings and use of restoration plans for more valuable buildings according to the estimated level of vulnerability in textured buildings in order to achieve the desired level of stability (restoration instead of renovation)

Attention to the types of structures and construction technology that have executive and supervisory skills in the region (native technology)

Reducing the weaknesses caused by the age of existing buildings through improvement and restoration instead of heterogeneous renovation (importance of age as an identity factor)

Systematic increase in the frequency of improved or renovated buildings under the supervision of experienced engineers (increase the penetration rate of specialized supervision and execution)

Updating of laws, regulations and building codes to the gradual and systematic learning of accidents (evolutionary approach to resilience and the realization of the spring cycle of crisis management)

Avoid creating any systematic heterogeneity, such as paying attention to the construction technology of the field, then determining the construction technology in the reconstruction, or modifying policies to determine the density (population, construction and height) in upstream programs and designs according to the characteristics of the contexts (knowing the context, then deciding on reconstruction)

Try to deal with the increase in population density in the neighborhood as well as in adjacent neighborhoods in order to reduce the problems caused by this type of density.

(High density is equal to high losses and damages as a result of reduced risk of escape and the possibility of evacuation of the injured and lack of open space for temporary accommodation)(Maintaining or decreasing the density in contrast to the strong tendency to increase it)

Improvement and renovation of existing public buildings with the aim of creating multiple uses and the possibility of providing services in the crisis management cycle (importance of public buildings in crisis management)

Pay attention to the fact that in service buildings, linear forms with strong structures and in buildings with housing, nuclear forms with strong structures should be used. (Application of public buildings according to their form)

Location of furniture and facilities for emergencies, especially for vulnerable groups such as ramps, escalators and furniture for the disabled, special furniture for children in public buildings (installation of furniture according to the efficiency of the building in crisis management)

Leaving empty space around the building and not connecting the building with other buildings to reduce vulnerability and thus provide quick relief in case of danger (pay attention to proximity and mutual privacy in building renovation) 


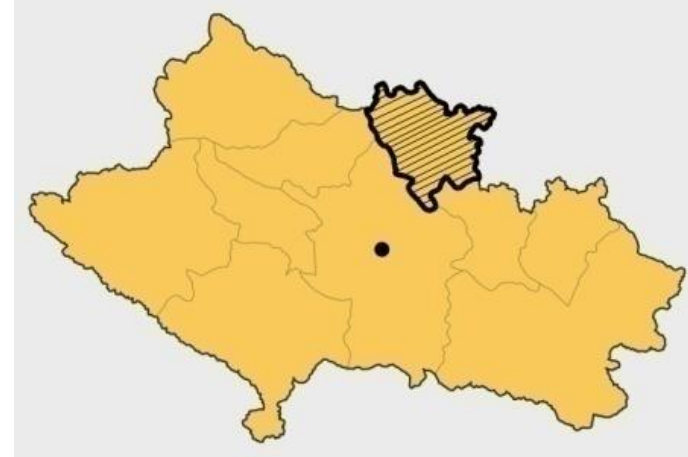

Figure 1. Geographical location of Borujerd city in Lorestan province

geographical location of Borujerd city in Lorestan province.

In figures 2 and 3 , the location maps of Borujerd in Lorestan province, the historical context in this city, and the Qadghoon neighborhood in the historical context of the city are presented.

As can be seen in the map, the study area of this research is the Qadghoon neighborhood, which ends at Razan Square and Sirus Street (Azadi) in the north, Saadi Street in the west, Imam Khomeini Boulevard in the south, and Sepah Street in the east.

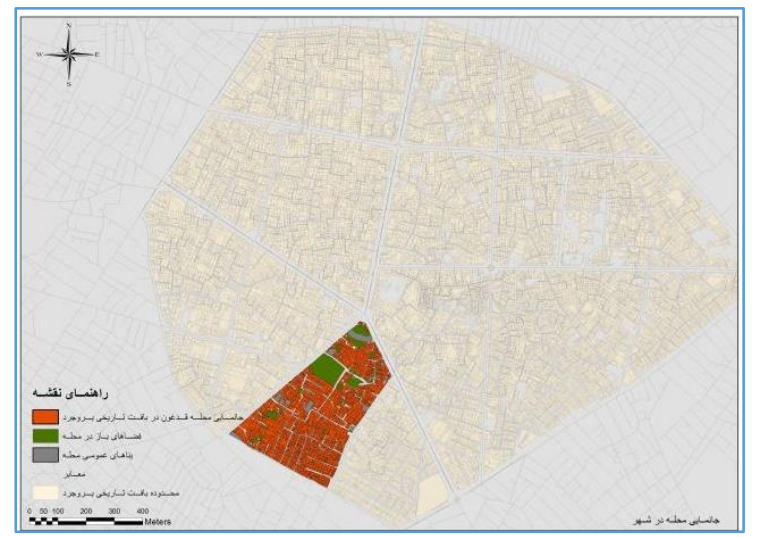

Figure 3. Location of Qadghoon neighborhood in the historical context of Borujerd (16)

\section{Findings}

Borujerd is defined as the fifth zone at the risk of earthquakes in Iran within the zoning of the earthquake hazard level. Qadghoon is one of the historical neighborhoods located at the center of this city. In the earthquake that struck Borujerd city in 2006, this neighborhood, due to its high vulnerability, was severely damaged. The damages continued increasingly during the

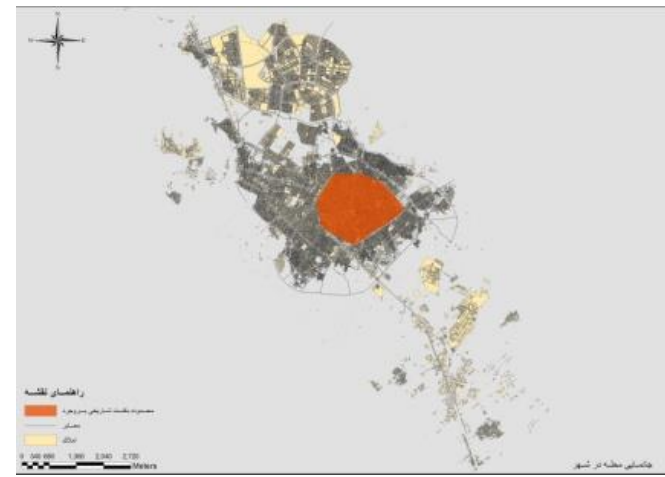

Figure 2. Borujerd city area and its historical context (16)

reconstruction process leading to the elimination of the homogeneous tissue of the neighborhood. Now, after 13 years, and huge reconstructions, many problems are still enduring. To describe the current conditions of the neighborhood, the prioritized indexes defining the vulnerability level of buildings on an urban scale were presented in the form of maps after conducting field studies and feeding the data into the GIS software, followed by statistical analysis the data were.

Representative maps of stability and strength of buildings in the Qadghoon area

Locating a symmetrical buildings and different forms in the neighborhood and the blocks

The assessment of these buildings was based on three maps, namely the existence of asymmetries in the plot plan, the frequency of asymmetries in the block, and different forms of public buildings. Figure 1depicts two types of buildings which were found in great numbers in this neighborhood. One group was the buildings with severe inherent geometric problem (According to the index explanations, the buildings which have irregular vertical and

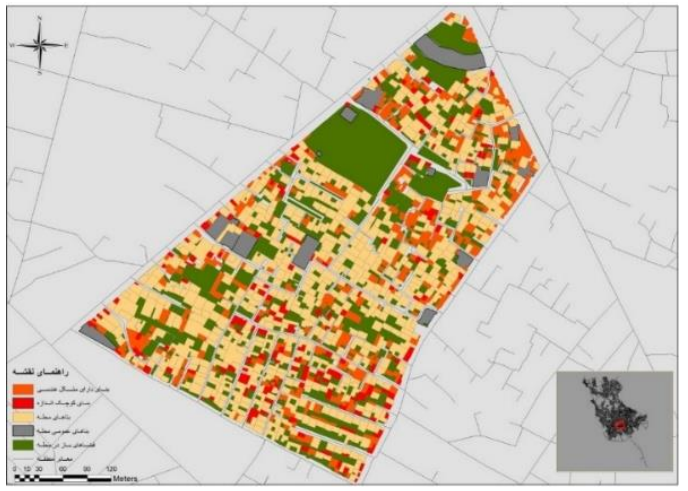

Figure 4. Locating buildings with geometric problems (authors) 


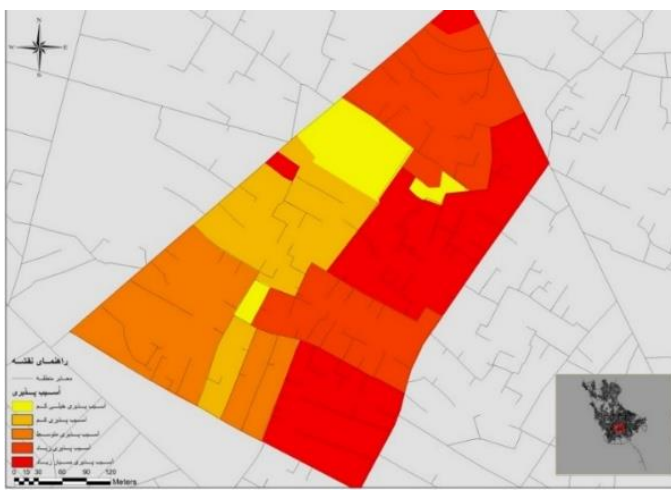

Figure 5. Location of blocks with irregular and unconventional buildings (authors)

horizontal dimensions and those that cannot tolerate the pass correction are considered geometrically irregular.) or that were problematic due to the corrections made after reconstruction processes, such as widening the carriageways. The second group consisted of small buildings, and consequently, of high vulnerability. Lack of geometric regularity and the smaller size (buildings with an area of lesser than 50 square meters including business and residential uses. See the table of extracted indexes.) of the building showed a complex seismic behavior that was much harder to be analyzed and predicted, compared to regular and simple buildings, which resulted in its higher vulnerability. On the other hand, these buildings confront the officials with greater difficulties (Due to the irregular structure which is in contrast with the regular structure of the reconstructed area and buildings, this issue causes an increase in the costs of the reconstruction process.) during the reconstruction process and cause a delay in reconstruction and a waste of resources.

Blocks with irregular buildings were also more

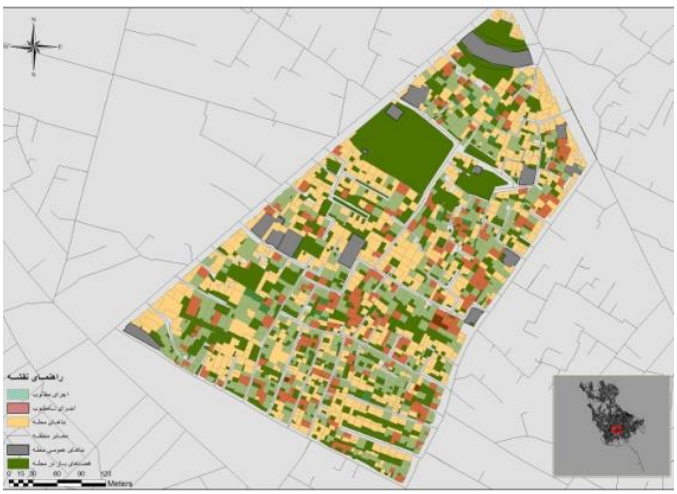

Figure 7. Locating of poorly constructed buildings (authors)

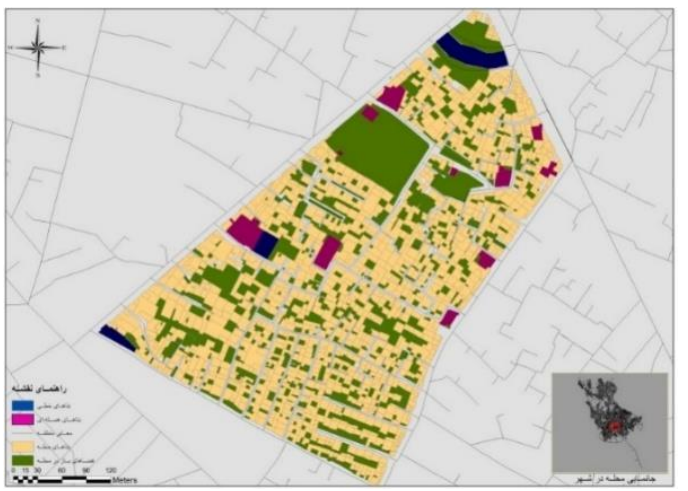

Figure 6. Locating various forms of public buildings (authors)

vulnerable during and after the earthquake and their reconstruction underwent greater delay. Figure 2 shows the percentage and number of irregular and unconventional buildings and categorizes the blocks based on this index. According to this figure, blocks number 13 and 1, with the highest frequency of more than $90 \%$ of the buildings, had the highest vulnerability. Among 109 buildings in block No. 1, 105 buildings were found asymmetric and unconventional and all the 4 buildings in block No. 13 were also asymmetric and irregular. Following that, blocks number 15, 10, 4, 3, and 2, had a great vulnerability with more than $80 \%$ of the irregular buildings, compared to all buildings in this neighborhood. In other words, block No. 2 with 137 buildings out of 171 buildings, block No. 3, with 4 buildings out of the total of 5, block No. 4 with 146 buildings out of 181, block No. 10 with 198 buildings out of 223, and block No. 15 with 11 buildings out of 13 were within this range of vulnerability. Block 12 with $70 \%$, block 8 with $60 \%$, block 6 with $56 \%$, block 9 with $55 \%$, block 5 with $45 \%$, block 7 with $43 \%$, and block 11 with

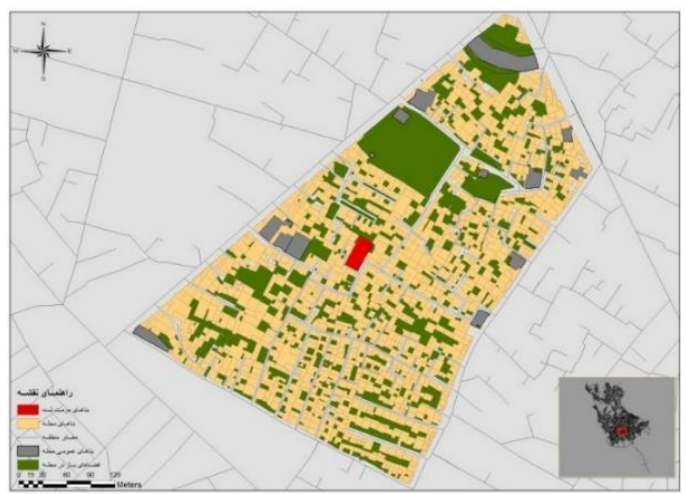

Figure 8. Locating restored building (authors) 


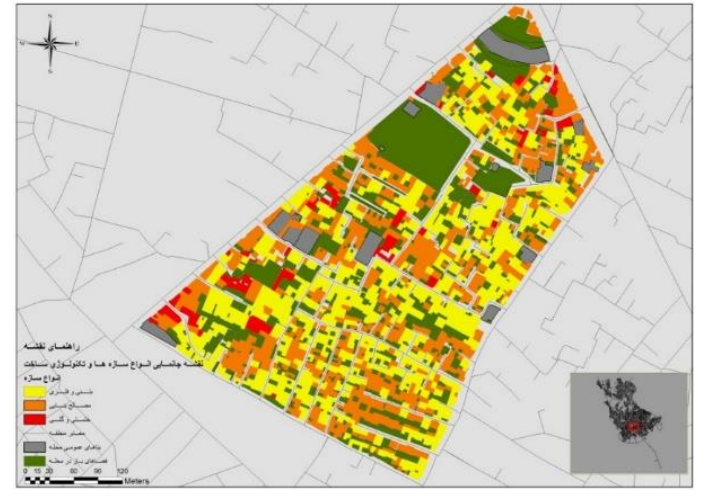

Figure 9. Types of construction and technology (authors)

$30 \%$ of irregular and geometrically problematic buildings (respectively, 108 out of 154, 21 out of 35,31 out of 156,23 out of 42,67 out of 149,16 out of 37 , and 3 out of 10) formed the next ranks of highly vulnerable buildings. Block 14, which was the green space, was analyzed as having the lowest rate of vulnerability in this index. Totally, out of 1,290 buildings in this neighborhood, 874 $(68 \%)$ buildings had geometric asymmetries. This amount, which formed one-fifth of the whole number of buildings in this neighborhood, indicated that with a score of 4.5 , the vulnerability was very high. Since different forms of public buildings perform different functions in different periods, it is important to investigate them from this point of view. According to Figure 4, 80\% and $20 \%$ of public buildings have nuclear and linear forms, respectively. Although linear forms were more vulnerable during the earthquake, since the number of such buildings was less in the neighborhood, the rate of vulnerability decreased. Therefore, according to the abovementioned issue and the greater number of nuclear buildings, the vulnerability number of 3.2 can be considered as an average indicator.

Overall, the total vulnerability number of this index was considered high (4 out of 5) due to the frequency of irregular and different forms of public buildings.

\section{Locating poorly constructed new buildings}

Weak construction remarkably enhances the amount of vulnerability during the earthquake. An increase in the number of losses and damages within the post-disaster time-span would double the amount of vulnerability. Figure 4 illustrates the buildings which were poorly reconstructed (the other hand, in addition to the present field

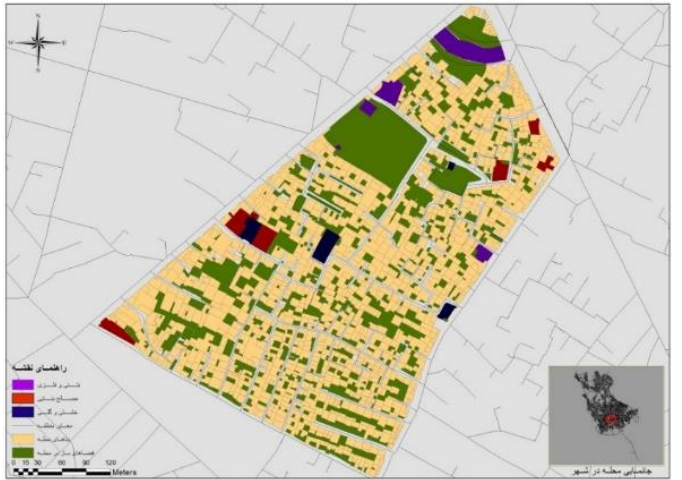

Figure 10. Locating types of construction technology (authors)

study, familiarity with construction conditions through life experience before the April 2006 earthquake in Borujerd and the presence of authors in this city, in the years after reconstruction and close observation of processes occurring, especially in the first years after the earthquake and the problems of this period, one of the most important of which was the lack of skilled and specialized personnel in the region, despite the high number of renovated buildings in this period, shows an intense decrease in the quality of construction in this period) after the earthquake due to several reasons, such as a lack of consistent and careful supervision of the reconstruction and/or an absence of expertise among the members of the reconstruction teams. These buildings incorporated $34 \%$ and $16 \%$ of the newly constructed and the total number of buildings in this area, respectively. Such statistics indicate the low-reliability coefficients of the newly constructed buildings and extensive waste of reconstruction budget. Overall, the vulnerability number in this index was obtained at 4 , which was high.

\section{Zoning the restoration of the area or locating the restored valuable buildings}

Along with the preservation of the heritage and identity of the land, restoration of historically valuable buildings would decrease the vulnerability of the area during the disaster. Additionally, protecting these buildings via restoration would increase the possibilities of future developments by tourism enhancement and plays a highly direct role in controlling poverty within the area. Although extensive restorations have been carried out during the reconstruction of the area, Figure 4 shows that $5 \%$ of the whole buildings in this area 
are made of brick (with a frequency of 64 buildings), most of which have architectural and identity values. Since only one out of all buildings was restored (See the zoning map of the restoration of the area or the locating of the restored buildings), the vulnerability number was estimated at 5, which was very high.

\section{Locating different structures and their construction technology}

The score of this index was extracted from two maps of private and public buildings of the area. If the vulnerability of the structures of the buildings within the area decreased, fewer losses would be experienced during the disaster. That is why it is believed that this index has a higher influence on vulnerability at the time of disaster. Based on the investigations of the area, the highest frequency of the type of construction materials was obtained for construction materials with $49 \%$, followed by concrete and metal structures with $46 \%$ of the whole buildings. The least frequent structures were related to the traditional structures made of bricks with a $5 \%$ frequency. Since those structures constructed with building materials were not restored and did not perform well during the seismic shocks, along with the high number of poorly constructed (See the map of locating the poorly constructed new buildings) new buildings and also brick structures that were not restored (See the zoning map of the area restoration or the locating of restored buildings), the vulnerability score of the neighborhood in this respect was calculated at 3.59 , which was considered average to a relatively high rate.

The effect of the high vulnerability score of public buildings is more obvious in different stages of the earthquake especially the postdisaster stage. In this area, 33\% of the whole public buildings were made of concrete and metal structures, and therefore, had low vulnerability against the earthquake. However, the structures made of building materials with a frequency of $40 \%$ had the highest score among the public buildings. Moreover, 27\% of the public buildings were made of brick, indicating a very high vulnerability index. These buildings should be restored and reconstructed before the occurrence of other disasters. The score of vulnerability in this respect was estimated at 3.61, which was average to relatively high. Overall, the vulnerability score obtained for the types of construction of buildings (private and public) was 3.6, which was average to relatively high.

\section{Map of the longevity of the buildings}

The long life of buildings can enhance the rate of vulnerability during the earthquake if they are not restored and reconstructed. Nevertheless, due to the scarce consistent technical supervision on the construction process of buildings before the earthquake, the buildings become even more vulnerable. This index not only increases the losses and damages rate within the area but also affects the vulnerability in the form of difficulties that might be experienced with regard to the consequent rescue and relief measures and the organization and reconstruction processes.

In this area, the buildings constructed after the earthquake, from 1976-85, and from 1986-2006 (i.e., before the earthquake) were rated in descending order with $45 \%, 25 \%$, and $24 \%$ frequency of the whole buildings. The buildings constructed before 1976, however, were placed last in this ranking order with a low frequency of $6 \%$. The statistics indicated the high rate of reconstruction and destruction, which were worthy of consideration in its due time. It can be concluded that with $55 \%$ of the buildings being constructed before the earthquake, the vulnerability level of the neighborhood was average to rather high with a score of 3.28.

\section{Supervision laws on construction}

The very existence of this index demands the necessary condition for a decline in the rate of building vulnerability. However, the sufficient condition is that the rules, which were reviewed on the previous map, need to be applied adequately. In conclusion, according to these rules, observing rigid supervision principles by the engineers licensed to supervise the process of reconstruction of all buildings in the present study led to a decline of vulnerability level to a very low point of 1 .

\section{Incompatible buildings in the area}

The presence of this index during the crisis causes an increase in the vulnerability of the area and is influential on the intervals before and after the disaster. According to the Figure 12, 29.9\% of the whole buildings are incompatibly constructed close to the vicinity of other buildings in that area. 


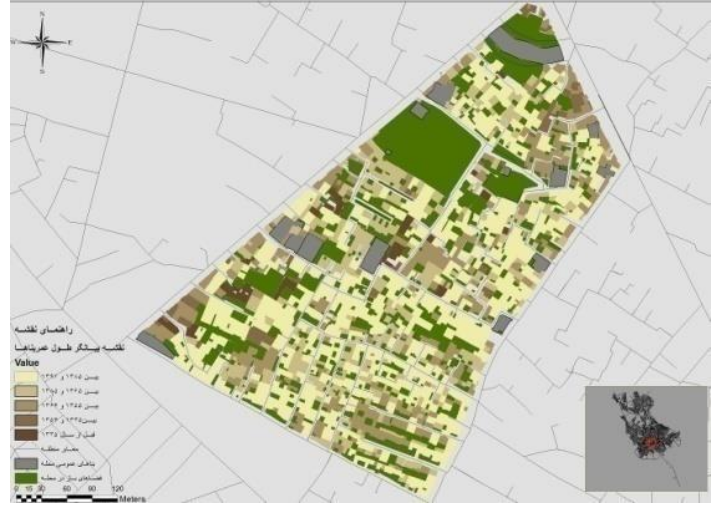

Figure 11. Longevity of the buildings (authors)

Different factors can cause this incompatibility, including the excessive worn out status of the buildings and breakdowns, extra height compared to the vicinity, large size, and formal contradictions. This amount of incompatible buildings and the way that they are spread throughout the area indicate a high vulnerability index reflected by the vulnerability number of 4 .

\section{Discussion and Conclusion}

Table 2 is prepared after careful vulnerability analysis of the existing buildings using prioritized and measurable indexes collected from specialized texts. The process of weighting these indexes was fulfilled through the use of AHP and calculation of the standardized weight number of the vulnerability of each index.

According to Table 2, the Qadghoon neighborhood has the highest vulnerability in the historical improvement index with a score of 5 out of 5. Considering the index of geometric irregularities, poor performance and heterogeneous structures in the texture, with the score of 4 out of 5 , was the next level of vulnerability. Furthermore, weak structures and high age of buildings with a score higher than 3 were in the next ranks of vulnerability. Finally, due to the existence of rules (however incomplete) and superior documents, there was the least vulnerability in this factor.

This table shows that the vulnerability score of the neighborhood in the area of existing buildings (private and public) is 3.52 from the range of 1 to 5 (with higher numbers indicating the greater vulnerability).In terms of how the post-disaster reconstruction process affects the reduction of vulnerability of urban buildings regarding the prioritized indicators, compared to the previous condition of the neighborhood, it should be

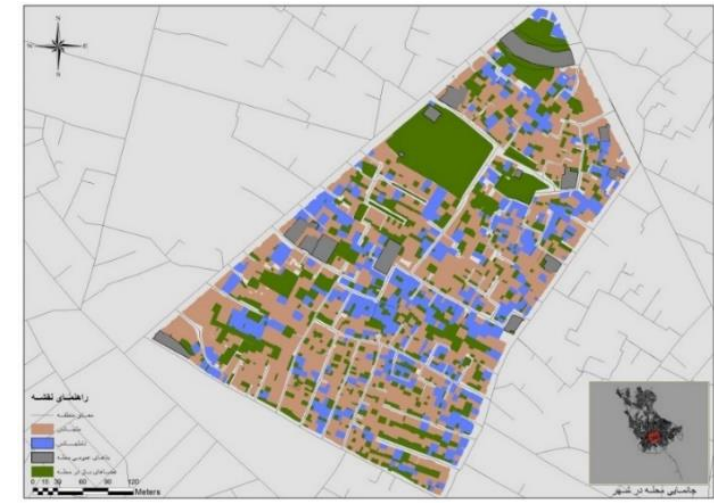

Figure 12. Locating incompatible buildings (authors)

mentioned that:

- From the point of view of the existing index of geometric and formal irregularities, there was a slight correction in the geometry of the parts, compared to the previous situation.

- From the point of view of poor performance index of new buildings, more than $45 \%$ of the previous buildings in the neighborhood were renovated in the context, which in the field study evaluation, this issue was determined that $34 \%$ of them are weak and has major defects in their construction.

- From the perspective of the Cultural Heritage Preservation Index, out of 64 former brick buildings in the neighborhood, only one historic house was restored, and other buildings had either been destroyed or abandoned during the post-disaster reconstruction and were in danger of being demolished.

- Regarding the index of types of structures and construction technology, considering the $46 \%$ frequency of new concrete and metal structures that theoretically have a low vulnerability, along with $49 \%$ of buildings with medium-sized building materials, the reduction of neighborhood vulnerability, were considered more appropriate in private buildings than other indicators, compared to the former conditions. It was revealed that $27 \%$ of the public buildings in this neighborhood were constructed by brick and $40 \%$ of them by other type of materials, that their reduction of vulnerability was less successful.

- From the perspective of the age index of existing buildings, due to the lack of reduction of vulnerability in 55\% of neighborhood buildings and renovation of $45 \%$ of these buildings, it can be seen that despite the high 
percentage of the renovation of existing buildings and reduced vulnerability in the neighborhood, it seems that the level of overall vulnerability of the buildings according to this index is far from the standard and has not yet been able to achieve the expected values of the reconstruction process.

- From the point of view of the existence of monitoring systems of engineers and specialists and the existence of monitoring codes and rules, which have become more complete during the post-disaster processes, it seems that the situation of the neighborhood has been improved and the vulnerability rate has been reduced.

- From the point of view of heterogeneity index in buildings, about $30 \%$ of textured buildings are heterogeneous in their proximity, in different ways. This situation has become more complicated during the reconstruction process due to the use of structural or elevating systems and other cases that are not compatible with the context. As it seems, from this point of view, not only a decreased vulnerability was not observed in the neighborhood but also there was an increase in this regard.

One of the most important priorities in conducting this research was answering the questions of this research. The first question sought to determine the vulnerability of neighborhood buildings in the priority indicators of the research. To respond to this question, it was found that the vulnerability of the neighborhood after more than a decade of the post-earthquake reconstruction process, based on the analysis of data obtained from research indicators in the AHP, was 3.25 out of 5 , that this score indicated the moderate upward vulnerability. On the other hand, this score showed the failure of this process in one of the most important indicators of reducing urban vulnerability, namely neighborhood buildings. This was usually performed by those in charge of post-disaster reconstruction, according to their engineering approach and conventional processes. It is also one of the most important considerations and allocation of financial-human resources, compared to other areas and scales. Putting together the vulnerability score of the building and the very high attention to the building, it would be possible to estimate the success rate of the reconstruction process in all urban organs. It is possible to have less success in other scales and urban organs by allocating fewer resources, such as roads, open spaces, facilities and equipment, and infrastructure.

The second question was designed according to the previous conditions of the neighborhood, and with a comparative view, the rate of reduction of vulnerability in priority indicators. Accordingly, it should be mentioned that after a separate review of the situation of vulnerability reduction in the priority indicators of the research, it was predicted that the level of vulnerability to disasters alone would be slightly reduced in the future. This rate of reduction of vulnerability, even in the indicators emphasizing the impact of the reconstruction process (single-building scale) and having a very high percentage of resource allocation was not acceptable at all and indicated the failure of the post-traumatic reconstruction process in this category of indicators and scale of single buildings.

In response to the third question of the research, which sought suggestions for the process of post-traumatic reconstruction on a single scale, as well as to learn in similar future processes, the following table is presented:

\section{Acknowledgments}

The authors appreciate the efforts of Ms. Farshideh Omidvari, who has played an effective role in all stages of this research, especially field surveys.

\section{Conflict of Interests}

The authors declare that there is no conflict of interest.

\section{References}

1. Habibi K, Ezzati M, Torabi K, Ezzatpanah B. Investigating the urban vulnerability against earthquake using Mihwp model-case study: 10th zone of Tabriz. Geography Plann 2017; 20(58):10118 [In Persian].

2. Hosseini A, Omidvari F. Analysis of the role of urban design in the crisis management cycle. Tehran: Architecture; 2017[In Persian].

3. Mittal V. Amendments in town \& country planning legislations for safety in natural hazard. New York: United Nations Development Programme; 2007. p. 36.

4. Wolfe MR. Urban scale vulnerability. Proceedings of the US-Italy colloquium on urban design and earthquake hazard mitigation, Rome, Italy; 1981.

5. Benarji T. Urban design and earthquake. California: 
University of California Press; 1993. P. 42-60.

6. Mohammadzadeh R. A study of the role of open space and transportation network in minimizing seismic vulnerability case study: Baqmisheh zone of Tabriz. Soffeh 2010; 20(50): 103-19. [In Persian].

7. Hosseini A, Omidvari F, Fallahi A, Ahari Z, Motawaf S. Urban facilities earthquake vulnerability assessment, case study: Qadghoon neighborhood of Borujerd. J Natl Environ Hazards 2019; 8 (21):187206 [In Persian].

8. Deputy of Urban Planning and Architecture of Tehran Municipality. Diagnosis of urban blocks with worn texture in Tehran. Tehran: Deputy of Studies and Planning of Tehran; 2008. [In Persian].

9. Ghanbari H, Nourian N. Earthquake damage reduction with emphasis on optimal location of special uses using GIS. Tehran: Imam Hussein University; 2009[In Persian].

10. Shireugene S, Ebrahimzadeh M. Crisis management and earthquake impact reduction in urban neighborhoods with dilapidated texture with simultaneous strategy. Tehran: Imam Hussein University; 2009. [In Persian].

11. Shieh E, Habibi K, Torabi K. Investigation of earthquake vulnerability of cities using the case study analysis method of District 6 of Tehran Municipality. Fourth International Conference of Geographers of the Islamic World, Tehran, Iran; 2010.P.12. [In Persian].

12. Ahadnejad M, Jalilpour S. Evaluation of external factors affecting the structural vulnerability of old cities to earthquakes (Case study: District 1 of Khoy city). National Seminar on the Application of GIS in Economic, Social and Urban Planning, Tehran, Iran; 2011. P. 1-12. [In Persian].

13. Monzavi M, Soleimani M, Tavalaei S, Chavoshi E. Vulnerability of city deteriorated districts of central Tehran to earth quake (case study of zone 12). Hum Geography Res Quart 2010; 73:1-18. [In Persian].

14. Hamidi M. The role of form, the model of the size of settlements in reducing the risks of earthquakes (recognition and analysis of the form of Rudbar city in vulnerability and efficiency during earthquakes). Tehran: Center for Iran Disaster Management Studies; 1997.P.70. [In Persian].

15. Hosseini A. A review of experiences of assessing urban physical vulnerability to earthquake. Fifth Conference on Civil Engineering, Architecture and Urban Development, Shiraz, Iran; 2017 [In Persian].

16. Omidvari F. Urban design framework of Qadghoon neighborhood of Borujerd with resilience approach. Tehran: Shahid Beheshti University; 2015 [In Persian].

17. Ghaderimotagh G, Shurjeh M. The position of councils in urban crisis management, Tehran: Islamic Republic News Agency; 2008 [In Persian].

18. Zebardast E, Mohammadi A. Locating relief centers in the occurrence of earthquakes using GIS. Tehran: University of Tehran; 2005. pp.5-16 [In Persian].

19. Golkar K. Adaptation of SWOT analytical technique for application in urban design. Soffeh 2005; 15(41):44-65[In Persian].

20. Brown C. The 21 st century urban disaster. Geneva: CHF International; 2012.

21. Saeed Nia A. The green book of the guide of municipalities. Tehran: Publications of the Organization of Municipalities and Villages of the Country; 2004 [In Persian].

22. Mercuri C. The organization, form and functions of urban systems in seismic risk evaluation. Munich, Germany: European Geosciences Union; 2007.

23. Habib F. The role of city form in reducing earthquake hazards. Islamic revolution housing foundation. Proceedings of the Second International Conference on Seismology and Earthquake Engineering, Tehran, Iran; 1991. pp.13-6. [In Persian].

24. Ahmadi $\mathrm{H}$. The role of urban planning in reducing the vulnerability of the city. Tehran: Housing and Revolution, Specialized Quarterly of the Housing Foundation of the Islamic Revolution; 2017. pp.6170. [In Persian]. 